\title{
The Effect of Different Intensities of Sub Maximal Aerobic Exercise on Proteinuria in Young Football Players
}

\author{
${ }^{1}$ Mohammad Ali Kohanpour, ${ }^{1}$ Maryam Vatandost, ${ }^{1}$ Fateme Zolfaghari, ${ }^{1}$ Maghsoud Peeri, \\ ${ }^{1}$ Mona Mirsepasi, ${ }^{2}$ Zohreh Mirsepasi, ${ }^{3}$ Abdolmahdi Nasirzade and ${ }^{3}$ Solmaz Khanmohammadi \\ ${ }^{1}$ Department of Exercise Physiology, Faculty of Physical Education and Sports Sciences, \\ Islamic Azad University, Central Tehran Branch, Tehran, Iran \\ ${ }^{2}$ Department of Physical Education, \\ Nasibeh Center of Higher Education and Teacher Training, Tehran, Iran \\ ${ }^{3}$ Department of Physical Education and Sport Science, Payam e Noor Universtiy, \\ P.O. Box 19395-3697 Tehran, Iran
}

\begin{abstract}
The purpose of this study was to determine the effects of different intensities of submaximal aerobic exercise on proteinuria in young football players. Ten volunteers of young football players (Age: $18 \pm 0.5$ years, weight: $64.42 \pm 3.64 \mathrm{~kg}$, height: $174 \pm 4 \mathrm{~cm}$ ) were selected and participated in three sessions of aerobic activities including $30 \mathrm{~min}$ of running at three different intensities, 55,70 and $85 \%$ of maximal heart rate. Before and $20 \mathrm{~min}$ after all three sessions, the amounts of urinary albumin, total protein, creatinine, $\beta_{2}$-microglobuline and protein to creatinine ratio were measured and investigated using analysis of variance with repeated measurements and paired-samples student t-test. With increasing exercise intensity, the protein content of urine increased. $\beta_{2}$-microglobuline significantly increased only for $85 \%$ of maximal heart rate. It seems that tubular proteinuria does not occur at lower intensities of activity. At lower intensities albuminuria and glomerular proteinuria take place and no proteinuria was observed for $<70 \%$ of maximal heart rate intensities. Urine protein to creatinine ratio in before and after each exercise was $<0.1$, respectively. Thus, proteinuria after aerobic sub maximal activity with three different intensities has the physiological range.
\end{abstract}

Key words: Proteinuria, aerobic exercise, albumin, $\beta_{2}$-microglobuline, protein to creatinine ratio, Iran

\section{INTRODUCTION}

Large proteins, such as globulin and albumin cannot pass through glomerular membrane and therefore are observed in very small amounts in urine but in case of glomerular damages their amounts in urine increase, a condition called glomerular proteinuria (Poortmans and Ouchinsky, 2006). Proteins with lower molecular weights such as $\beta_{2}$-microglobulin and lysosome easily pass through glomerule but due to sufficient tubular reabsorption, these proteins are also found in very small amounts in urine (Poortmans and Ouchinsky, 2006; Poortmans et al., 1996). In medical conditions accompanied by tubular disorders the presence of these proteins increases, a condition called tubular proteinuria. It is observed that the proteinuria is increased following heavy physical activities (Kocer et al., 2008).

Renal disorders caused by sports activities first were reported in 1878 after observing the incidence of proteinuria in soldiers who had hard physical activities. Post-exercise proteinuria is a well-recognized phenomenon among human athletes, the severity of which has depended on the intensity of the exercise (Poortmans et al., 1996; Poortmans, 1984). It has been suggested that the presence of excess protein excretion in urine may be due to a disturbance in the selective permeability in the glomerulus associated or not with a saturation process in the reabsorption of the filtered protein load (Poortmans et al., 1996; Hardwicke et al., 1970). These assumptions have been based on renal clearance of high and low molecular mass plasma proteins (Poortmans et al., 1996). In renal disease in which glomerular permeability is increased, a larger excretion of proteins with high molecular mass has been observed (Poortmans et al., 1996). It has been reported that when proteinuria is a consequence of tubular dysfunction, the amount of protein filtered by the glomeruli remains stable and the proteins with low molecular mass appear in larger

Corresponding Author: Mohammad Ali Kohanpour, Department of Exercise Physiology,

Faculty of Physical Education and Sports Sciences, Islamic Azad University, Central Tehran Branch, Tehran, Iran 
quantity due to their incomplete tubular reabsorption (Poortmans et al., 1996; Peterson et al., 1969). During exercise the plasma flow rate in kidneys decrease and this decrease is directly proportional to exercise intensity. It seems that sympatic nerves and also endocrine systems play a role in this process. As a result of decreasing renal blood flow rate, the glomerular filtration rate decreases too (Poortmans, 1984). There exists a close relation between plasma decline and the presence of albumin in urine, i.e., albuminuria (Estivi et al., 1992). Alyea and Parish Jr. (1958) reported that most sportsmen attending either contact or non-contact sports activities are observed to have a variety of proteins in their urine (Alyea and Parish $\mathrm{Jr}$., 1958). Glomerular type and both glomerular and tubular types have been observed after moderate and heavy exercises, respectively (Boileau et al., 1980; Poortmans, 1985). Poortmans and Vancalck (1978) reported excretion of proteins after short strenuous exercise. They reported increase in total protein and albumin content as well as renal clearance increase after exercise (Poortmans and Vancalck, 1978). Carroll and Temte (2000) reported that proteinuria is a common problem among adults attending sports activities. It was also reported that fever, high intensity physical or sports activities, body water loss, mental stress and serious diseases are benign and indangerous factors that may cause proteinuria. According to him proteinuria may be categorized as glomerular, tubular and overflow of which glomerular type is most pronounced (Carroll and Temte, 2000). Post-exercise proteinuria is a transient process, lasting approximately $1 \mathrm{~h}$ and the maximum proteinuria occurs in 20-30 min after exercise (Poortmans et al., 2006).

Although, quantitative assessment of proteinuria from $24 \mathrm{~h}$ urine collection still remains a gold standard for urinary protein estimation, besides protein to creatinine ratio provided a very useful, simple and convenient method for quantitative assessment of protein and can replace $24 \mathrm{~h}$ urine collection method which used in present study (Garg et al., 2004). As a result of the fact that proteinuria increases following intense physical activities and that excessive excretion of proteins in urine may cause renal damage. One of the main issues that many researchers are concerned with around the world is the impact of physical activities on renal performance in particular the proteinuria. The purpose of the present study was to investigate, the response of different intensities of aerobic exercise on proteinuria in young football players.

\section{MATERIALS AND METHODS}

Subjects: The subjects of this study consisted of 10 young male soccer players competing that their characteristics are shown in Table 1. These football players in the past 3 years had playing experience in the
Table 1: Average and standard deviation of subjects characteristics

\begin{tabular}{lccccc}
\hline $\begin{array}{l}\mathrm{BMI} \\
\left(\mathrm{kg} \mathrm{m}^{-2}\right)\end{array}$ & $\begin{array}{c}\mathrm{VO}_{2} \max \\
(\mathrm{mL} / \mathrm{kg} / \mathrm{min})\end{array}$ & $\begin{array}{c}\text { Height } \\
(\mathrm{cm})\end{array}$ & $\begin{array}{c}\text { Weight } \\
(\mathrm{kg})\end{array}$ & $\begin{array}{c}\text { Age } \\
\text { (y ears })\end{array}$ & $\mathrm{N}$ \\
\hline $21.27 \pm 2.14$ & $47.6 \pm 4.83$ & $174 \pm 4$ & $64.42 \pm 3.64$ & $18 \pm 0.5$ & 10 \\
\hline
\end{tabular}

premier league the Fars province of Iran. Announcing call for youth football teams in the Premier League of province and elaborating the purposes of the present study, 10 soccer players eligible to participate in the study after receiving informed consent and medical examinations and tests were selected. The subjects were non-smokers with no background of renal, heart and liver, etc., disorders and had not a surgery or medical treatment in 6 months before conducting the experiments of this study. Indeed, they were healthy and athletic people who had regular practice at least 3 days week ${ }^{-1}$. All of them had no experiment of playing in a better or worse league than the best league of Fars province. Then use the personal information questionnaire, information such as age, sex, sports background obtained and healthy of kidney and urinary system was confirmed by physician.

Exercise program: The 5 days before the research protocol, aerobic power of the subjects was measured using Bruce test on treadmill (Maud and Foster, 1995). Then, they met in the first exercise session. Three sessions of aerobic exercise concluded $30 \mathrm{~min}$ running on treadmill with three different intensity. These three exercise sessions were interfered with $48 \mathrm{~h}$ rest periods. In order to avoid misleading results, caused by the effects of exercise sessions on each other, the order of exercise sessions was chosen on a random basis. Each participant attended $30 \mathrm{~min}$ of running on treadmill at 55, 70 and $85 \%$ of maximal heart rate. Maximum heart rate using the Eq. 208 (0.7 age) were obtained (Tanaka et al., 2001). During the study, the subjects were kept in a house prepared for them and they were asked to rest and avoid any physical activity. They were also asked to avoid take meals full of fat, proteins and caffeine at nights before sampling days. In the morning of sampling days, each subjects should empty his bladder and then rest sitting without any physical activity. They should be present at exercise location $2 \mathrm{~h}$ before each test. They drink enough water before and after each exercise session in order to produce urine for sampling. All protocols were approved by the Graduate Council of Faculty of Physical Education and Sports Science, Islamic Azad University, Central Tehran.

Taking urine samples and analysis: Urine samples were taken before and $20 \mathrm{~min}$ after each exercise session. The samples were stored in special containers at $4^{\circ} \mathrm{C}$ and all 
samples study 30 main proteinuria indices were measured and analyzed. Albumin, total protein and creatinine as glomerular damage indices and $\beta_{2}$-microglobuline as tubular damage index. The concentration of urinary albumin was measured by Immunoturbidomentric Method using American Diasorin kit with a sensitivity of $3 \mathrm{mg} \mathrm{L}^{-1}$, urinary total protein concentration by Elisa Comasi-blue (Brad Ford) Method using American Diasorin kit with a sensitivity of $1 \mathrm{mg} \mathrm{dL}-1$, urinary creatinine concentration by Spectophotometry Method (based on the Jaffe Model) using American Diasorin kit with a sensitivity of $31 \mathrm{mg} \mathrm{dL}^{-1}$ and urinary $\beta_{2^{-}}$ microglobuline concentration by Chemiluminescense Method using American Diasorin kit with a sensitivity of $0.12 \mathrm{mg} \mathrm{L}^{-1}$. Urinary protein to creatinine ratio also was calculated by dividing the total protein and creatinine in each sample by units of $\mathrm{mg} \mathrm{dL}^{-1}$.

Statistical methods: In the present study in order to make sure that the data distribution is normal and in order to determine the parametric or non-parametric statistical test, the resulted data was first investigated using Kolmogorov-Smirnov test and it was determined that the data posses normal distribution. So for variability between three exercise sessions with three different intensity. Analysis of Variance (ANOVA) with repeated measurements was used. In case of observing significant difference, in order to determine the difference location and reduce the error paired-samples Student t-test with
Bonferroni corrections was also utilized. Also, check the variability within each of the three exercise sessions paired-samples Student t-test was used.

\section{RESULTS}

The amounts of urinary albumin, total protein, Creatinine, $\beta_{2}$-microglobuline and protein to creatinine ratio before and after all three exercise sessions are shown in Table 2. Table 3 showed the results of Analysis of Variance (ANOVA) with repeated measurements between the three exercise sessions also Table 4 showed pairedsamples Student t-test for each exercise session.

Based on current research findings with increased intensity of exercise, urinary albumin excretion increased significantly $(\mathrm{p}=0.038$ and $\mathrm{p}=0.036$ for $20 \mathrm{~min}$ after and the mean difference before and after exercise, respectively). The maximum differences was observed in range of the $55-70 \%$ of maximum heart rate $(\mathrm{p}=0.012$ and $\mathrm{p}=0.014$ for $20 \mathrm{~min}$ after and the mean difference before and after exercise, respectively) and also between 55-85\% of maximum heart rate $(\mathrm{p}=0.027$ and $\mathrm{p}=0.026$ for $20 \mathrm{~min}$ after and the mean difference before and after exercise, respectively). As well as, aerobic activity with the intensity of the $55 \%$ of maximum heart rate yields to non-significant increase of urinary albumin $(\mathrm{p}=0.248)$ and activities with the intensity up to the 70 and $85 \%$ of maximum heart rate yields to significant increase of urinary albumin ( $\mathrm{p}=0.018$ and $\mathrm{p}=0.046$, respectively).

Table 2: Average and standard deviation of proteinuria in before and after exercise sessions

\begin{tabular}{|c|c|c|c|c|c|c|}
\hline \multirow[b]{2}{*}{ Variables $\left(\mathrm{mg} \mathrm{dL}^{-1}\right)$} & \multicolumn{2}{|c|}{ Exercise with $55 \%$ MHR } & \multicolumn{2}{|c|}{ Exercise with $70 \% \mathrm{MHR}$} & \multicolumn{2}{|c|}{ Exercise with $85 \% \mathrm{MHR}$} \\
\hline & Before & After & Before & After & Before & After \\
\hline Albumin & $0.810 \pm 0.630$ & $1.150 \pm 1.090$ & $0.830 \pm 0.550$ & $3.960 \pm 3.450$ & $0.780 \pm 0.640$ & $5.420 \pm 5.93$ \\
\hline Total protein & $2.750 \pm 2.390$ & $2.550 \pm 1.200$ & $2.720 \pm 2.320$ & $4.580 \pm 2.870$ & $2.710 \pm 2.410$ & $10.050 \pm 7.86$ \\
\hline Creatinine & $95.000 \pm 56.07$ & $116.000 \pm 30.07$ & $95.500 \pm 55.65$ & $188.500 \pm 51.31$ & $95.000 \pm 56.07$ & $219.500 \pm 70.25$ \\
\hline$\beta 2$ microglobuline & $0.054 \pm 0.030$ & $0.057 \pm 0.030$ & $0.057 \pm 0.040$ & $0.059 \pm 0.030$ & $0.056 \pm 0.030$ & $0.108 \pm 0.05$ \\
\hline Protein to creatinine ratio & $0.032 \pm 0.028$ & $0.023 \pm 0.013$ & $0.031 \pm 0.026$ & $0.024 \pm 0.018$ & $0.031 \pm 0.028$ & $0.040 \pm 0.021$ \\
\hline
\end{tabular}

Table 3:Results of Analysis of Variance (ANOVA) with repeated measurements between the sixth exercise sessions

\begin{tabular}{|c|c|c|c|c|c|c|}
\hline Variables & Pre/Post & Sum of squares & $\mathrm{df}$ & Mean squares & F-test & $p$-values \\
\hline \multirow[t]{3}{*}{ Albumin } & Pre & 0.009 & 1.224 & 0.007 & 0.2450 & 0.678 \\
\hline & Post & 94.202 & 2.000 & 47.101 & 3.9570 & $0.038^{*}$ \\
\hline & $\mathrm{D}$ & 95.181 & 2.000 & 47.59 & 4.0300 & $0.036^{*}$ \\
\hline \multirow[t]{3}{*}{ Total protein } & Pre & 0.009 & 1.224 & 0.007 & 0.2450 & 0.678 \\
\hline & Post & 300.973 & 1.089 & 276.303 & 8.4420 & $0.015^{*}$ \\
\hline & $\mathrm{D}$ & 303.752 & 1.086 & 729.714 & 8.4180 & $0.015^{*}$ \\
\hline \multirow[t]{3}{*}{ Creatinine } & Pre & 1.667 & 1.000 & 1.667 & 1.0000 & 0.343 \\
\hline & Post & 56431.667 & 2.000 & 28215.833 & 9.2790 & $0.002 *$ \\
\hline & $\mathrm{D}$ & 56295 & 2.000 & 28147.5 & 9.1850 & $0.002 *$ \\
\hline \multirow[t]{3}{*}{$\beta_{2}$-microglobuline } & Pre & 0.00005807 & 1.280 & 0.00004535 & 1.0810 & 0.339 \\
\hline & Post & 0.016 & 1.017 & 0.016 & 5.5330 & $0.042^{*}$ \\
\hline & $\mathrm{D}$ & 0.084 & 1.001 & 0.084 & 3.1280 & 0.111 \\
\hline \multirow[t]{3}{*}{ Protein to creatinine ratio } & Pre & 0.00002885 & 2.548 & 0.00001132 & 1.0880 & 0.367 \\
\hline & Post & 0.004 & 1.655 & 0.002 & 4.6470 & $0.032 *$ \\
\hline & $\mathrm{D}$ & 0.003 & 1.398 & 0.0002 & 3.5010 & 0.078 \\
\hline
\end{tabular}

*The mean difference is significant at the 0.05 level; $\mathrm{D}=$ Means difference before and after activity (Delta) 
Res. J. Biol. Sci., 6(11): 590-596, 2011

Table 4: Results of paired-samples Student t-test for each exercise session

\begin{tabular}{lcccc}
\hline Variables & Exercise sessions & t-test & df & p-values \\
\hline Albumin & $55 \% \mathrm{MHR}$ & 1.237 & 9 & 0.248 \\
& $70 \% \mathrm{MHR}$ & 2.888 & 9 & $0.018^{*}$ \\
& $85 \% \mathrm{MHR}$ & 2.311 & 9 & $0.046^{*}$ \\
Total protein & $55 \% \mathrm{MHR}$ & 0.245 & 9 & 0.812 \\
& $70 \% \mathrm{MHR}$ & 1.440 & 9 & 0.184 \\
& $85 \% \mathrm{MHR}$ & 2.742 & 9 & $0.023^{*}$ \\
Creatinine & $55 \% \mathrm{MHR}$ & 1.036 & 9 & 0.327 \\
& $70 \% \mathrm{MHR}$ & 3.284 & 9 & $0.009^{*}$ \\
& $85 \% \mathrm{MHR}$ & 4.212 & 9 & $0.002^{*}$ \\
$\beta_{2}$-microglobuline & $55 \% \mathrm{MHR}$ & 2.055 & 9 & 0.070 \\
& $70 \% \mathrm{MHR}$ & 1.869 & 9 & 0.094 \\
& $85 \% \mathrm{MHR}$ & 2.492 & 9 & $0.034^{*}$ \\
Protein to & $55 \% \mathrm{MHR}$ & 1.156 & 9 & 0.277 \\
creatinine ratio & $70 \% \mathrm{MHR}$ & 0.650 & 9 & 0.532 \\
& $85 \% \mathrm{MHR}$ & 1.179 & 9 & 0.269 \\
\hline
\end{tabular}

*The mean difference is significant at the 0.05 level

Based on current research findings with increased intensity of activity, urinary excretion of total protein significantly increased $(\mathrm{p}=0.015$ and $\mathrm{p}=0.015)$ for $20 \mathrm{~min}$ after and the mean difference before and after exercise, respectively. The maximum differences was observed in range of the $55-70 \%$ of maximum heart rate $(\mathrm{p}=0.013$ and $\mathrm{p}=0.012)$ for $20 \mathrm{~min}$ after and the mean difference before and after exercise, respectively and also between $55-85 \%$ of maximum heart rate $(p=0.013$ and $p=0.013$ for $20 \mathrm{~min}$ after and the mean difference before and after exercise, respectively). As well as, aerobic activity with the intensity of the 55 and $70 \%$ of maximum heart rate yields to non-significant increase of total protein $(\mathrm{p}=0.812$ and $\mathrm{p}=0.184$, respectively) and activities with the intensity of $85 \%$ of maximum heart rate yields to significant increase of total protein $(\mathrm{p}=0.023)$.

Based on current research findings with increased intensity of exercise, urinary creatinine excretion increased significantly $(p=0.002$ and $p=0.002)$ for $20 \mathrm{~min}$ after and the mean difference before and after exercise, respectively. The maximum differences was observed in range of the $55-70 \%$ of maximum heart rate $(\mathrm{p}=0.002$ and $\mathrm{p}=0.003)$ for $20 \mathrm{~min}$ after and the mean difference before and after exercise, respectively and also between $55-85 \%$ of maximum heart rate $(p=0.003$ and $p=0.003)$ for $20 \mathrm{~min}$ after and the mean difference before and after exercise, respectively. As well as, aerobic activity with the intensity of the $55 \%$ of maximum heart rate yields to non-significant increase of urinary albumin $(p=0.327)$ and activities with the intensity up to the 70 and $85 \%$ of maximum heart rate yields to significant increase of urinary albumin $(\mathrm{p}=0.009$ and $\mathrm{p}=0.002$, respectively). Based on current research findings with increased intensity of activity, $\beta_{2}$-microglobolinuria significantly increased for $20 \mathrm{~min}$ after exercise $(\mathrm{p}=0.042)$ but there was observed no significant difference between mean value of $\beta_{2}$-microglobolin in after and before of exercise $(\mathrm{p}=0.111)$. Most of the difference was observed between 55 and $85 \%$ of maximum heart rate about 20 min after activity $(\mathrm{p}=0.035)$. As well as, aerobic activity with the intensity of the 55 and $70 \%$ of maximum heart rate yields to non-significant increase of urinary $\beta_{2}$-microglobolin $(p=0.070$ and $p=0.094$, respectively) and activities with the intensity of $85 \%$ of maximum heart rate yields to significant increase of urinary $\beta_{2}$-microglobolin $(\mathrm{p}=0.034)$.

\section{DISCUSSION}

In the present study albuminuria, total proteinuria, creatininuria and $\beta_{2}$-microglobulinuria were observed to increase significantly with increasing exercise intensity. Poortmans and Labilloy (1988) reported that the post-exercise proteinuria is more related to activity intensity. Poortmans and Vancalck (1978) showed that intense activity result in urinal excretion of albumin and total protein.

Kramer et al. (1988) reported that albuminuria increases following heavy sports activities. This indicates glomerular origin of proteinuria (Poortmans and Vancalck, 1978). Delforge also showed that the more the exercise intensity the more serious is proteinuria. This conclusion was then confirmed by Poortmans and Labilloy (1988). In the present study increasing exercise intensity resulted in increasing $\beta_{2}$-microglobulinuria. This is in agreement with previous studies which indicated that tubular proteinuria occurs with increasing physical activity intensity (Poortmans and Vancalck, 1978). Poortmans and Vancalck (1978) and Montelpare et al. (2002) showed that periodic physical load increases $\beta_{2}$-microglobulinuria. After exercise high renal clearance of $\beta_{2}$-microglobulinuria has been observed. This indicates that post-exercise proteinuria has also a tubular origin (Poortmans and Vancalck, 1978).

Poortmans et al. (1988) showed $\beta_{2}$-microglobuline along with increasing blood lactate (Portmans et al., 1988). Suzuki and Ikawa (1991) stated that decreasing blood $\mathrm{pH}$ as a result of organic acids may change glomerular permeability and prevent tubular absorption (Suzuki and Ikawa, 1991). This may be one of the reasons of increasing proteinuria as a result of heavy physical activities because we know that heavy physical activities make body environment more acidic. These findings have been confirmed with Turgut et al. (2003). However, the exercise protocol was not related to increasing body acidity. $\beta_{2}$-microglobulinuria significantly increased at an activity intensity of $85 \%$. Perhaps several amino acids contribute to tubular reabsorption disorder (Naderi and Reilly, 2008). Under rest conditions, $>95 \%$ of filtered proteins are reabsorbed by proximal tubular cell and 
converted to amino acids (Naderi and Reilly, 2008). All amino acids are present in overflow proteinuria and tubular reabsorption is prevented as a result of absorption capacity completion (Naderi and Reilly, 2008).

In addition, the result of the present study suggest that aerobic activity at $55 \%$ of maximal heart rate increases albuminuria but not significantly. Some researcher have shown that following light physical activities proteinuria is observed to increase only in some unhealthy for example diabetic, sedentary people and this is not the case for healthy ones (Poortmans and Labilloy, 1988).

This is in agreement with the fact that all participants of the study were young, healthy sportsmen. However, aerobic activities at 70 and $85 \%$ of maximal heart rate caused significant increase in albuminuria in the present study and this increase was maximum for exercise with $85 \%$ maximal heart rate. This is in agreement with findings of Clerico et al. (1990), Feldt-Rasmussen et al. (1985), Poortmans and Vancalck (1978) and Kramer et al. (1988). In the present study, aerobic activities at 55 and $70 \%$ of maximal heart rate were not strong enough to increase total proteinuria significantly but the increase was significant at $85 \%$ of maximal heart rate.

Poortmans and Vancalck (1978), De Palo et al. (2002) and Turgut et al. (2003) showed that urinary excretion of proteins increases following physical activities and this may be related to renal clearance increase. According to the results of the present study, creatinuria increased as a result of exercise at 70 and $85 \%$ of maximal heart rate. This is in agreement with Turgut et al. (2003) who reported significant post-exercise proteinuria in both young men and women.

The narrowing of renal arteries due to epinephrine and norepinephrin increase duing exercise may be one of the reasons of post-exercise proteinuria increase (Poortmans, 1984).

As a result of renal blood flow decrease during exercise glomerular filtration rate also decreases and regarding that this decrease is smaller that renal blood flow decrease, the filtration fraction increases and as a result passing through glomerular membrane becomes easier for high molecular weight proteins (Poortmans, 1984). Increase in plasma rennin activity that is observed during hard physical activities and is a result of glomerular sympathetic excitement may affect post-exercise proteinuria (Creeth et al., 1963; Poortmans, 1985). The mediation of kallikrein, an enzyme of Kinin System which is closely related to Renin-Angiotensin System may increase the permeability of glomerular membrane. The loss of capillary wall negative charge may also be effective (Creeth et al., 1963; Poortmans, 1985).
Zambraski et al. (1981) studied variations of renal ciallic acids in response to exercise and stated that exercise decreases glomerular electrostatic resistance and may justify part of increase in passage of macromolecules. The role of factors like prostaglandins is also of importance and if people take medicines that block prostaglandins production during exercise, proteinuria decreases significantly provided that there is no renal hemodynamic change (Feldt-Rasmussen et al., 1985). Gunduz et al. (2003), Senturk et al. (2007) and Kocer et al. (2008) observed increase in post-exercise proteinuria. The findings of Poortmans and Vancalck (1978) and Clerico et al. (1990) suggest that post-exercise proteinuria is very transient. Although, the main factor affecting post-exercise proteinuria is activity intensity (Kramer et al., 1988; Poortmans et al., 1978), the activity duration is also effective (Boileau et al., 1980; Clerico et al., 1990).

Based on the findings of this study, although the amounts of urinary protein to creatinine ratio were observed after three meeting of $20 \mathrm{~min}$ of activity with three different intensity. But researchers observed no significant difference when reserachers compared the mean value of these three meetings in before and after exercise. This finding is also approved in previous studies (Kristal et al., 1998). Kristal et al. (1998) found significant linear relationship between proteins to creatinine ratio and proteinuria of $24 \mathrm{~h}$. Protein to creatinine ratio of $<0.1$ and $0.1-1$ and $>1$ may be used in order to identify a range of physiologic, pathologic and nephrotic proteinuria (Kristal et al., 1998). It has been concluded that the urine protein to creatinine is more reliable to estimate the quantitative proteinuria (Kristal et al., 1998). It is also know that ratio $<0.2$ shows proteinuria in limited range and proteinuria $>3.5$ is the scope of nephrotic proteinuria (Garg et al., 2004). Thus, the protein to creatinine ratio is used to detect significancy of proteinuria (Saikul et al., 2006). Thus, the results show that proteins to creatinine ratio had physiologic domain and has significant difference with the pathologic and nephritic values thus it is not malicious (Kristal et al., 1998).

\section{CONCLUSION}

In the present study increasing exercise intensity was significantly effective on proteinuria. $\beta_{2}$-microglobulinuria was only significant in exercise at $85 \%$ of maximal heart rate and this suggests that tubular proteinuria does not take place at lower intensities. At lower intensities albuminuria and glomerular proteinuria occur and at intensities $<70 \%$ of maximal heart rate no proteinuria takes place. As well as was found that none of the training 
sessions has any significant change in the ratio of urinary protein to creatinine and values obtained from all samples indicating a $<0.1$, respectively. Accordingly, the maximum aerobic activity in the present study yields to physiological proteinuria in young soccer players that is not malicious. Post-exercise proteinuria could not be a limiting factor for physical activities. Furthermore, in order to come up with more thorough conclusions it seems that more researches are required.

\section{REFERENCES}

Alyea, E.P. and H.H. Parish Jr., 1958. Renal response to exercise-urinary findings. JAMA, 167: 807-813.

Boileau, M., E. Fuchs, J.M. Barry and C.V. Hodges, 1980. Stress hematuria: Athletic pseudonephritis in marathoners. Urology, 15: 471-474.

Carroll, M.F. and J.L. Temte, 2000. Proteinuria in adults: A diagnostic approach. Am. Family Physician, 62: 1333-1340.

Clerico, A., C. Giammattei, L. Cecchini, A. Lucchetti and L. Cruschelli et al., 1990. Exercise-induced proteinuria in well-trained athletes. Clin. Chem., 36: $562-564$.

Creeth, J.M. and R.A. Kekwick, F.V. Flynn, H. Harris and E.B. Robson, 1963. An ultracentrifuge study of urine proteins with particular reference to the proteinuria of renal tubular disorders. Clin. Chim. Acta, 8: 406-414.

De Palo, E.F., R. Gatti, F. Lancerin, E. Cappellin and G. Solda et al., 2002. Urinary insulin-like growth factor I in athletes before and after physical exercise and in sedentary subjects. Clin. Chim. Acta., 322: 51-57.

Estivi, P., R. Urbino, C. Tetta, G. Pagano and P. CavalloPerin, 1992. Urinary protein excretion induced by exercise: Effect of a mountain agonistic footrace in healthy subjects. J. Sports. Med. Phys. Fitness, 39: 196-200.

Feldt-Rasmussen, B., L. Baker and T. Deckert, 1985. Exercise as a provocative test in early renal disease in type 1 (insulin-dependent) diabetes: Albuminuric, systemic and renal haemodynamic responses. Diabetologia, 28: 389-396.

Garg, S., A.K. Gupta, A. Rohtgi and S.K. Sharma, 2004. Evaluation of random urine sample protein-cretinine ratio as an index of quantitative proteinuria. JK. Sci., 6: 134-137.

Gunduz, F., O. Kuru and U.K. Senturk, 2003. Effect of nitric oxide on exercise-induced proteinuria in rats. J. Applied Physiol., 95: 1867-1872.
Hardwicke, J., Cameron J.S., J.F. Harrison, B. Hulme and J.F. Soothill, 1970. Proteinuria Studied by Clearances of Individual Macromolecules. In: Proteins in Normal and Pathological Urine, Manuel, Y., J.P. Revillard, H. Betuel(Eds.). Karger, Basel, Switzerland, pp: 111-152.

Kocer, G., U.K. Senturk, O. Kuru and F. Gunduz, 2008. Potential sources of oxidative stress that induce post-exercise proteinuria in rats. J. Applied Physiol., 10: 1152-1176.

Kramer, B.K., M. Kernz, K.M. Ress, M. Pfohl and G.A. Muller et al., 1988. Influence of strenuous exercise on albumin excretion. Clin. Chem., 34: 2516-2518.

Kristal, B., S.M. Shasha, L. Labin and A. Cohen, 1998. Estimation of quantitative proteinuria by using the protein/creatinine ratio in random urine samples. Am. J. Nephrol., 8: 198-203.

Maud, P.J. and C. Foster, 1995. Physiological Assessment of Human Fitness. 2nd Edn., Human Kinetics, Champaign, IL, USA., Pages: 319.

Montelpare, W.J., P. Klentrou and J. Thoden, 2002. Continuous versus intermittent exercise effects on urinary excretion of albumin and total protein. J. Sci. Med. Sport, 5: 219-828.

Naderi, A.S.A. and R.F. Reilly, 2008. Primary care approach to proteinuria. J. Am. Board Family Med., 21: $569-574$.

Peterson, P.A., P.E. Evrin and I. Berggard, 1969. Differentiation of glomerular, tubular and normal proteinuria: Determinations of urinary excretion of beta-2-microglobulin, albumin and total protein. J. Clin. Invest., 48: 1189-1198.

Poortmans, J.R. and D. Labilloy, 1988.. The influence of work intensity on postexercise proteinuria. Eur. J. Applied Physiol., 57: 260-263.

Poortmans, J.R. and B. Vancalck, 1978. Renal glomerular and tubular impairment during strenuous exercise in young women. Eur. J. Clin. Invest., 8: 175-178.

Poortmans, J.R. and M. Ouchinsky, 2006. Glomerular filtration rate and albumin excretion after maximal exercise in aging sedentary and active men. J. Biol. Sci. Med. Sci., 61: 1181-1185.

Poortmans, J.R., 1984. Exercise and renal function. Sport Med., 1: 125-153.

Poortmans, J.R., 1985. Postexercise proteinuria in humans: Facts and mechanisms. JAMA, 253: 236-240.

Poortmans, J.R., H. Brauman, M. Staroukine, A. Verniory, C. Decaestecker and R. Leclercq, 1988. Indirect evidence of glomerular/tubular mixed-type postexercise proteinuria in healthy humans. Am. J. Phsyiol. Renal. Physiol., 254: 277-283.

Poortmans, J.R., N. Mathieu and P. De Plaen, 1996. Influence of running different distances on renal glomerular and tubular impairment in humans. Eur. J. Applied Physiol. Occup. Physiol., 72: 522-527. 
Saikul, S., B. Wiriyasirivaj, P. Charoenchinont, 2006. First 4-hour urinary protein- creatinine ratio for diagnosis of significant proteinuria in preeclampsia. J. Med. Assoc. Thai, 89: S42-S46.

Senturk, U.K., O. Kuru, G. Kocer and F. Gunduz, 2007. Biphasic pattern of exercise-induced proteinuria in sedentary and trained men. Nephron Physiol., 105: 22-32.

Suzuki, M. and S. Ikawa, 1991. The mechanisms of exercise-induced proteinuria-relationship between urinary excretion of proteins and lactate after exhaustive exercise. Nippon Jinzo Gakkai Shi., 33: 357-364.
Tanaka, H., K.D. Monahan, D.R. Seals, 2001. Predicted maximal heart rate revisited. J. Am. Coll. Cardiol., 37: 153-156.

Turgut, G., B. Kaptanoglu, S. Turgut, O. Genc and S. Tekinturk, 2003. Influence of acute exercise on urinary protein, creatinine, insulin-like growth factor-I (IGF-I) and IGF binding protein-3 concentrations in children. Tohoku J. Exp. Med., 201: 165-170.

Zambraski, E.J., M.C. Bober, J.E. Goldstein, C.S. Lakas and M.D. Shepard, 1981. Changes in renal cortical sialic acids and colloidal iron staining associated with exercise. Med. Sci. Sports, 13: 229-232. 